\section{Effect of PDGF-BB, IGF-I Growth Factors and their Combination Carried by Liposomes in Tooth Socket Healing}

Fernando Antônio Mauad de Abreu', Cynthia Lopes Ferreira', Gerluza Aparecida Borges Silva1 ${ }^{1}$ Camila de Oliveira Paulo², Melissa Nunes Miziara², Frank Ferreira Silveira ${ }^{3}$, José Bento Alves ${ }^{1,2}$

\begin{abstract}
This work evaluated the bone-forming potential of the platelet-derived growth factor isoform BB (PDGF-BB), insulin-like growth factor I (IGF-I), and mixed PDGF-BB/IGF-I delivered in liposomes compared with phosphate buffered saline (PBS), in the healing process of rat tooth sockets. One hundred and twelve Wistar rats were randomized into 7 groups of 16 animals each and were evaluated at 3, 7, 14 and 21 days after extraction of the maxillary second molars. The left sockets were treated with PBS (P), empty liposome (L), IGF-I in PBS (IP), IGF-I in liposome (IL), PDGF-BB in PBS (PDP), PDGF-BB in liposome $(\mathrm{PDL})$ and both growth factors (GFs) together within liposomes (PDIL). The right sockets were filled with blood clot (BC). Histological and histomorphometric analyses were used to evaluate the formation of new bone and blood vessels. Immunohistochemistry was performed to evaluate the expression of osteocalcin and vascular endothelial growth factor (VEGF) during bone repair. Data were tested statistically using a Tukey's test according to a Dunn's analysis and Mann-Whitney U test followed by Kruskal-Wallis one-way analysis. Results were considered significant when $p<0.05$. A significantly higher percentage of bone trabeculae and a higher number of blood vessels were observed in the IL, PDL and PDIL groups $(p<0.05)$. However, these GF-liposome groups had statistically similar results. Immunohistochemical assays first detected osteocalcin and VEGF expression at 3 days followed by a peak at 7 days. Lower immunoreactivity levels were observed in the $B C$, $L, P, I P$ and PDP groups compared with the IL, PDL and PDIL groups $(p<0.05)$. The results suggest that GFs carried by liposomes, either in isolated or mixed forms, enhanced the healing process in rat tooth sockets. The differential expression of the osteogenic markers VEGF and osteocalcin in the early phases of bone healing support these findings.
\end{abstract}

'Laboratory of Oral and Development Biology, Department of Morphology, Biological Sciences Institute, UFMG - Federal University of Minas Gerais, Belo Horizonte, MG, Brazil ${ }^{2}$ Laboratory of Biopathology and Molecular Biology, UNIUBE - University of Uberaba, Uberaba, MG, Brazil ${ }^{3}$ Laboratory of Oral Biology, Department of Dentistry, PUCMG Pontifical Catholic University of Minas Gerais, Belo Horizonte, MG, Brazil

Correspondence: Dr. Frank Ferreira Silveira, Avenida Dom José Gaspar, 500, Coração Eucarístico, 30535-901 Belo Horizonte, MG, Brasil. Tel: +55-031-3319-4444. e-mail: frankfoui@uol.com.br

Key Words: growth factor, PDGF, IGF, liposome, bone repair.

\section{Introduction}

After tooth extraction, alveolar bone resorption is followed by size and shape remodeling (1) and leads to progressive and irreversible reduction in the height and width of the alveolar ridge, which can cause problems for dental implant placement. Regenerative bone techniques with autografts, allografts and xenografts have been used as alternatives to diminish alveolar bone resorption $(2,3)$.

Growth factors (GFs) are proteins responsible for regulating the cellular stages of tissue regeneration $(4,5)$. During the bone healing process several GFs, such as platelet-derived growth factor (PDGF), insulin-like growth factor (IGF), transforming growth factor $\beta$ (TGF $\beta$ ), bone morphogenetic protein (BMP) and fibroblast growth factor (FGF), are released and act as mitogenic and angiogenic signals during the initial steps of bone regeneration (6).

IGF is an important factor for tissue regeneration. IGF plays an essential role in the general growth and maintenance of the body bone frame, by promoting local differentiation of bone cells and stimulating osteogenesis by the activation of the osteocalcin promoter, a protein secreted by osteoblasts that plays a role in mineralization, as well as it works as a negative regulator of bone formation. Specifically, IGF-I has been shown to promote the differentiation of bone cells in autocrine and paracrine fashions $(4,7)$.

PDGF is known to have a role in angiogenesis because it is an effective activator of osteoblasts, fibroblasts and endothelial cells. This glycoprotein exists in five different isoforms and is naturally abundant inside the bone matrix (8). PDGF is highly mitogenic and has been used to heal bone defects, alone or in association with different biomaterials (9). The PDGF isoform BB (PDGF-BB), considered the universal PDGF because of its ability to bind to all known receptor isotypes (5), works as a central connector between the pathways, and could thus be used as a powerful therapeutic agent for controlling osteogenesis during bone regeneration (10). Because IGFs may be used as adjuvant factors to enhance bone repair, and considering that the application of cytokines is similar to the natural pattern of GFs released during bone healing, combining IGF-I with PDGF may be a promising strategy to promote 
bone regeneration in bone defects around implants or after periodontal bone loss (4).

The tissue-engineering field focused on a search for efficient GF delivery systems, because the current strategies using tissue scaffolds provided limited results, and demands are increasing for treatments that reduce damage to the patient (11). Liposomes are versatile small spherical vesicles used to carry small drug molecules, proteins, nucleotides or plasmids in Biology, Biochemistry and Medicine (12). These small spherical vesicles can be produced from cholesterols, nontoxic surfactants, sphingolipids, glycolipids, long chain fatty acids and even membrane proteins (13), and they present advantageous properties, such as biodegradation, integration with lipophilic and hydrophilic molecules and the possibility of directing and controlling drug delivery (11). Our research group has recently demonstrated that epidermal growth factor (EGF) carried by liposomes enhanced osteoclast recruitment and increased orthodontic tooth movement, until fourteen days (12-14).

At present, no data are available regarding the actions of PDGF-BB, IGF-I and the combination of these two GFs with liposome on alveolar bone tissue after tooth extraction. The objective of this study was to evaluate the bone-forming potential of PDGF-BB, IGF-I and mixed PDGF-BB/IGF-I, associated with liposome or phosphate buffer saline (PBS) and the efficacy of liposome for growth factor delivery in healing tooth sockets of rats after extraction of the maxillary second molar, by histological and morphometric analyses. Vascular endothelial growth factor (VEGF) and osteocalcin expression were also evaluated, considering their potential to indicate bone repair.

\section{Material and Methods}

\section{PDGF-BB and IGF-I Liposome Preparation}

PDGF-BB and IGF-I liposomes were prepared according to Alves et al. (13), as follows. The GFs were dissolved in $1 \mathrm{~mL}$ of $10 \mathrm{mM}$ acetic acid containing $0.1 \%(\mathrm{w} / \mathrm{v})$ bovine serum albumin (BSA) at a final concentration of $0.2 \mu \mathrm{g} / \mathrm{mL}$ and stored at $-20^{\circ} \mathrm{C}$. The liposomes were obtained by sonication, using a solution of $12.0 \mathrm{mg} / \mathrm{mL}$ dipalmitoyl phosphatidyl choline (DPPC) and $1.2 \mathrm{mg} / \mathrm{mL}$ lysophosphatidyl choline (LPC) dissolved in $4 \mathrm{~mL}$ of chloroform and $10 \mu \mathrm{L}$ of PDGFBB or IGF-I solution, to produce homogeneous unilamellar vesicles with an approximately $100 \mathrm{~nm}$ diameter.

\section{Animal Sampling and Surgical Protocol}

One hundred and twelve male Wistar rats (Rattus norvegicus) weighing 250-300 g were included in this study. Concerning the limitation of the animal model compared with human, the rat alveolar bone has often been used as an ideal tissue for studying bone remodeling because this bone balances resorption and bone formation, maintains similar spatial orientation of these activities and has a high bone turnover rate.

The animals were maintained in plastic cages with access to food and water ad libitum. Prior to the surgical procedures, they were allowed to acclimatize to the laboratory environment. All animal handling procedures followed the Brazilian College of Animal Experimentation Guidelines and the study was approved by the Ethics Committee in Animal Experimentation of the Federal University of Minas Gerais (Protocol \#207/2009). Rats were anesthetized with a mixture of 10\% ketamine and 2\% xylazine $(1: 1,0.1 \mathrm{~mL} / 100 \mathrm{~g}$ body weight, i.m.) and subjected to maxillary second molar (right and left) extraction.

\section{Study Design}

The animals were randomly chosen and divided into 7 groups of 16 animals each as follows: P: administration of $1 \mu \mathrm{L}$ of PBS alone; L: administration of empty liposomes in $1 \mu \mathrm{L}$ of PBS solution; PDP: administration of $20 \mathrm{ng}$ of PDGF$\mathrm{BB}$ in $1 \mu \mathrm{L}$ of PBS solution; IP: $20 \mathrm{ng}$ of IGF-I in $1 \mu \mathrm{L}$ of PBS solution; PDL: $20 \mathrm{ng}$ of PDGF-BB + liposomes in $1 \mu \mathrm{L}$ of PBS solution; IL: 20 ng of IGF-I + liposomes in $1 \mu \mathrm{L}$ of PBS solution; and PDIL: 20 ng of IGF-I + 20 ng of PDGF-BB + liposomes in $1 \mu \mathrm{L}$ of PBS solution. Each solution was injected into the left sockets using a micro-syringe (Hamilton, Bonaduz, Switzerland). To avoid interfering with the delicate healing site, suture was not used after the surgical procedure and the rats were maintained immobilized in the supine position for approximately $4 h$, the duration of anesthesia and time for clot formation and stabilization. In addition, the animals received pasty chow for 2 days after surgery (14) to prevent displacement and/or disjunction of the blood clot. The right sockets from all animals were used as a control (blood clot - BC), without drug administration.

At days 3, 7, 14 and 21 after drug administration, four animals from each group were sacrificed by decapitation under anesthesia with 10\% ketamine hydrochloride (Dopalen ${ }^{\circledR}$; Vetbrands, São Paulo, SP, Brazil) and 2\% xylazine hydrochloride (Ronpum ${ }^{\oplus}$; Bayer, São Paulo, SP, Brazil) both drugs were $0.1 \mathrm{~mL} / 100 \mathrm{~g}$ body weight, delivered intramuscularly. The animals were used for histological, morphometric and immunohistochemical analyses.

\section{Tissue Processing}

After fixation, the maxillars were decalcified in a decalcifying solution of 10\% ethylenediamine tetraacetic acid (EDTA; Sigma-Aldrich, Munich, Germany) for 3 months. After that time, the tissues were briefly washed in running tap water, dehydrated and embedded in paraffin. Each sample was serially sliced into $5 \mu \mathrm{m}$ sections along the sagittal plane. Sections were mounted on glass slides and stained with hematoxylin eosin (HE) for 
histological and morphometric analyses or processed for immunohistochemistry. The sections were first observed on a light microscope (Axiostar Plus; Carl Zeiss, Jena, Germany) and analyzed by considering, for both control and experimental sockets, the patterns of organization and maturation of the connective tissue that fills the alveoli, presence of bone cells (osteoblasts, osteoclasts), newly formed bone tissue and blood vessels, and detection of inflammatory reactions. Usually, maxillary second molars present 4 roots: two distal and two medial. According to Mendes et al. (15), each socket was anatomically divided into apical, middle and cervical thirds (Fig. 1).

\section{Histomorphometric Analysis}

The morphometric analysis was performed according to previous works $(13,16)$, as follows. At least 3 randomly chosen sections were evaluated for each group. The images were obtained from apical (bottom), middle and cervical (upper) thirds of the distal root of the sockets (Fig. 1). Afterwards, the total area of each sample was measured and the trabecular area was determined. The percentage of trabecular bone area of each captured field was obtained by dividing the trabecular area by the total area using the AxioVision release 4.8 software (Carl Zeiss). The number of blood vessels was counted as previously described (13), using a grid with vertical and horizontal lines placed on the photomicrograph, with the aid of a confocal assistant 4.02 software (Chapel Hill, NC, USA). Vessels located on the grid line intersections were counted by a trained person as described by Reis-Filho et al. (16). The histological evaluation was performed several times by the examiner and the experienced researcher confirmed the results. The examiner was considered a trained counter only after his evaluation of the results reached $90 \%$ similarity.

\section{Immunohistochemistry Analysis}

Additional sections were mounted on glass slides and processed for immunohistochemistry, as previously described (13), to evaluate VEGF and osteocalcin expression. Briefly, slides were pretreated with 3-aminopropyltriethoxysilane (Sigma-Aldrich) immersed for $3 \mathrm{~min}$ in xylene to eliminate the paraffin, dehydrated in absolute alcohol and rehydrated with Tris-buffered saline (TBS) (Sigma-Aldrich). The sections were then rinsed in TBS and immersed in 3\% hydrogen peroxide in methanol for $10 \mathrm{~min}$ and incubated for $30 \mathrm{~min}$ at $90{ }^{\circ} \mathrm{C}$ for antigen detection. Slides were incubated in $2 \%$ bovine serum albumin (Sigma-Aldrich) for $30 \mathrm{~min}$ at room temperature to reduce non-specific binding. The slides were then incubated with anti-VEGF ([C-1] sc7269; Santa Cruz Biotechnology Inc., Santa Cruz, CA, USA) or anti-osteocalcin antibodies (Mouse monoclonal [OC430] ab-13418; ABCAM Cambridge, UK) for $2 \mathrm{~h}$ at $37^{\circ} \mathrm{C}$ and then rinsed with TBS three times for 3 min each. Sections were incubated with the appropriate secondary biotinylated antibody from Link System (Universal LSAB ${ }^{\mathrm{TM}}+\mathrm{Kit} / \mathrm{HRP}, \mathrm{Rb} /$ Mo/Goat K0690-1; Dako A/S, Glostrup, Denmark) for 30 $\min$ at $37^{\circ} \mathrm{C}$. After washing, the sections were incubated with peroxidase-conjugated streptavidin for $30 \mathrm{~min}$ at room temperature. Next, the slides were treated with a solution containing $\mathrm{H}_{2} \mathrm{O}_{2}(0.05 \%)$ and $1 \mathrm{mg} / \mathrm{mL}$ DAB (1,4-dideoxy1,4-imino-D-arabinitoldiaminobenzidine; Sigma-Aldrich) for $30 \mathrm{~min}$, and then rinsed in Tris-HCl buffer $(\mathrm{pH}=7.4)$. Slides were counterstained with Mayer's hematoxylin, dehydrated and mounted. Staining specificity was tested by omission of the primary antibody. To determine the amount of immunostained cells, randomly chosen sections were measured for both experimental and control sides. The slide images were obtained using a capture plate and a microscope (Axiostar Plus, Carl Zeiss) interfaced with a personal computer and AxioVision release 4.8 software (Carl Zeiss).

The intensity of immunostaining was assessed individually in a blind fashion by 2 trained examiners (kappa index 0.91) (17). The immunostaining reaction was classified according to the relative staining intensity as no immunoreactivity (zero), weak but visible staining intensity [1], moderate staining intensity [2] or strong staining intensity [3].

\section{Statistical Analysis}

The collected data were statistically tested using a Tukey's test according to a Dunn's analysis and MannWhitney U non-parametric test followed by Kruskal-Wallis one-way analysis. All groups were evaluated three times, and results were considered significant when $p<0.05$.

\section{Results}

Following the criteria recommended for reliability of biological analysis of bone repair, a histological evaluation of the healing process was performed at portions of the distal root, by scanning the central part of the injured sockets, including the apical (bottom), middle and cervical (upper) thirds. Bone formation at the remaining periodontal ligament was not considered (Fig. 1).

During the wound healing process, classic typical tissue repair events were observed, such as blood clot rising and maturation, infiltration of the coagulum by fibroblasts, and establishment of a provisional matrix. In the 3-day rat sockets, the alveoli from the BC, L, P, PDP and IP groups were filled with a blood clot on the apical, middle and cervical thirds (Fig. 2A). When compared with those groups, the alveoli from the PDL, IL and PDIL groups exhibited histological traits compatible to advanced bone repair, which included the replacement of most of the blood clot 
with a provisional matrix consisting of dilated blood vessels, mesenchymal cells, fibers and scattered inflammatory cells (Fig. 2B). No pattern differentiation among the groups treated with GF-liposome was observed.

At day 7 the formation of trabeculae in the $B C, L, P$, PDP and IP groups (Fig. 3A) was verified rising from the alveoli base and the presence of cellular connective tissue including small vessels and intertwined fine collagen fibers. However, the progress of alveoli repair in the groups

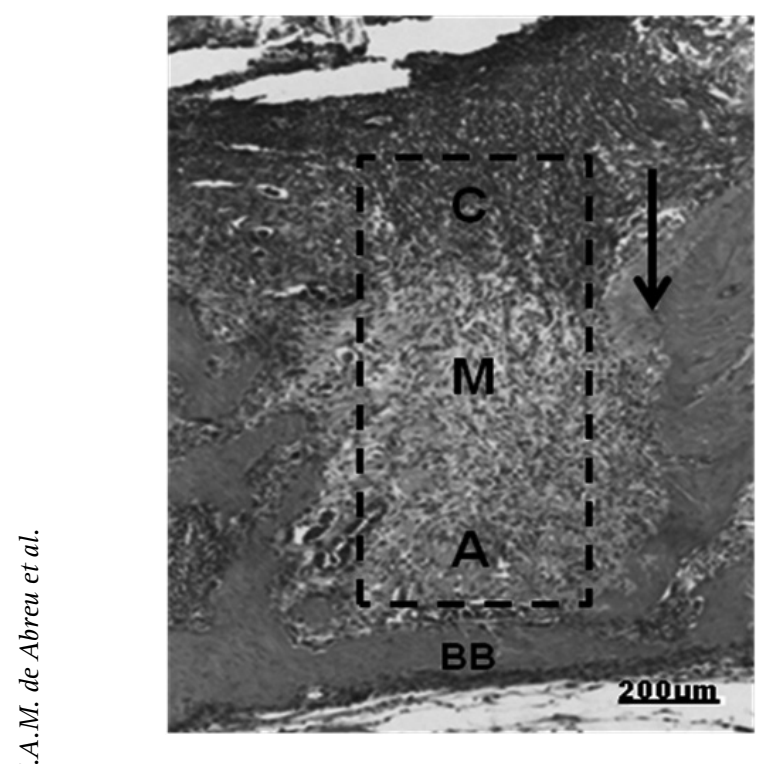

Figure 1. Histological section of a rat socket showing the delimited area assessed in this study. A: apical third; M: middle third; and C: cervical third of alveoli. BB: basal bone. The black arrow indicates a portion of the periodontal ligament, which was not included in the analysis. Bar $=200 \mu \mathrm{m}$. receiving GFs in liposomes was characterized by complete replacement of the blood clot, with connective tissue exhibiting homogenous matrix, and presented advanced organization of the first primary trabeculae at the apical and middle thirds of the alveoli (Fig. 3B).

At 14 days after surgery, the $B C, L, P, P D P$ and IP groups had alveoli in a pronounced process of bone formation, where the primary osseous tissue filled the apical and middle alveoli (Fig. 4A), while the PDL, IL and PDIL groups were found to be more advanced, showing mature bone trabeculae in the osteon and medullar spaces (Fig. 4B).

New bone tissue partially filled all alveoli groups at 21 days after extraction. Therefore, the GF-liposome treated groups (PDL, IL and PDIL) always showed a more enhanced stage of development. The histometric studies showed a statistically higher percentage $(\mathrm{p}<0.05)$ of newly formed bone trabeculae in alveoli (Fig. 5) at 7, 14 and 21 days after the surgical procedure, as well as an enhanced number of vessels (Fig. 6) $(p<0.05)$ at 7 days after the surgical procedure in sockets from the PDL, IL and PDIL groups compared with the BC, L, P, IP and PDP groups.

The spatial and temporal expressions of osteocalcin and VEGF, two important molecules involved in wound repair, were also evaluated in alveoli from all tested groups. A stronger expression of VEGF at 7 days in groups treated with GF-liposome (isolated or in combination) compared with the remaining assessed groups was identified (Figs. 7A and $7 \mathrm{~B}$ and Table 1). Then decrease was observed in the next stages ( 14 and 21 days). Histoquantitative data confirmed the histological analysis and indicated a statistically significant difference $(p<0.05)$ in VEGF expression at the
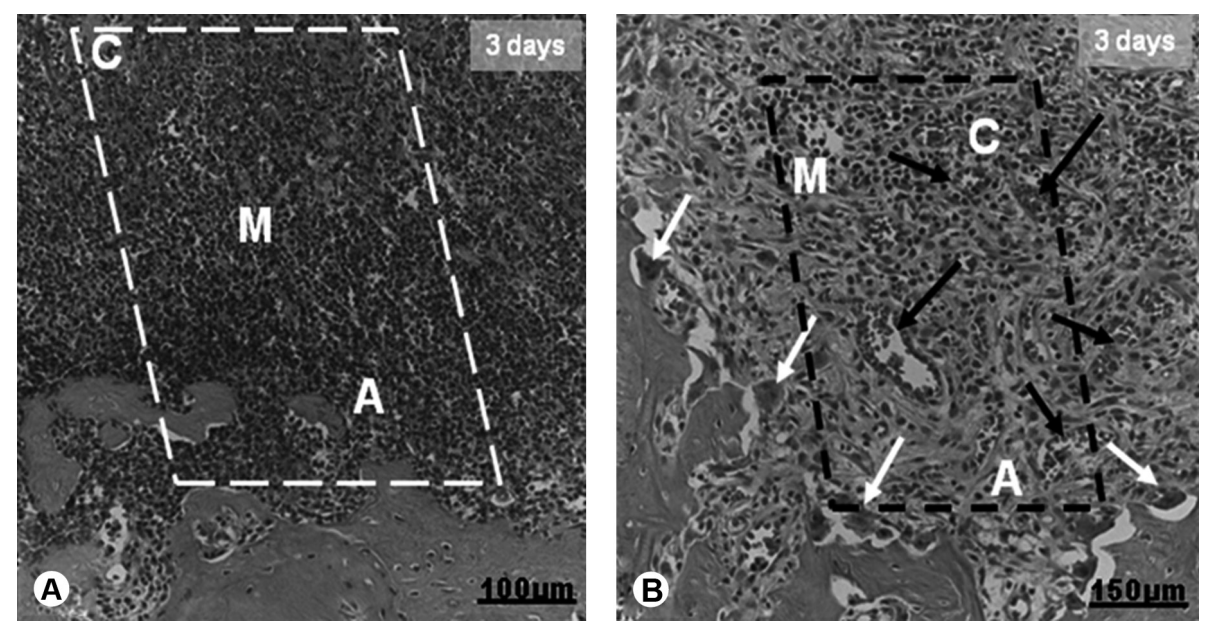

Figure 2. Representative HE-stained photomicrographs of groups at 3 days after the surgical procedure. (A) BC, L, P, IP, PDP groups. The apical, medium and cervical thirds of the alveoli are filled with a blood clot and intense inflammatory infiltrate. Bar $=100 \mu \mathrm{m}$. (B) $1 \mathrm{~L}$ and PDL groups showing the medium and apical thirds of the alveoli, a connective tissue with a fine fiber network and dilated blood vessels (black arrows) among fibroblastoid cells, which characterize the provisional matrix. The cervical third maintains the acute inflammatory infiltrate. Bar $=150 \mu \mathrm{m}$. The white-delimited area represents the extracted socket from all treatment groups and for each observation period, to allow a comparative evaluation of the treatment outcome. A: apical third; M: middle third; and C: cervical third of alveoli. Black arrows: vessels. White arrows: osteoclasts. 
7-day stage. Osteocalcin expression in the alveoli from the PDL, IL and PDIL groups peaked at 7 days in connective tissue cells filling the alveoli, and the labeling remained in the osteogenic cells and osteoblasts during the next stages, as shown in Figures $8 \mathrm{~A}$ and 8B, and Table 1.

\section{Discussion}

The physiological events that follow the "wound healing cascade" led to the integration of a wide variety of GFs to recapitulate and mimic the natural microenvironments of tissue formation and repair. Because the physiology of
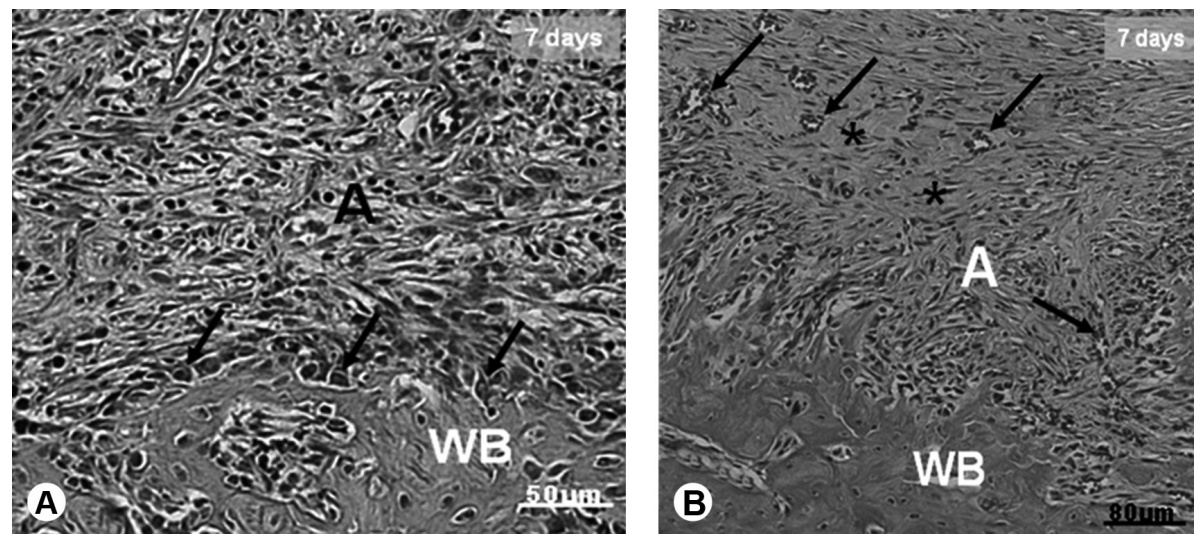

Figure 3. Representative HE-stained photomicrographs of groups at 7 days after the surgical procedure. (A) BC, L, P, IP and PDP groups showing the deposition of immature osseous matrix, characterizing the primary trabeculae of woven bone (WB); the arrows indicate osteoblasts near to the trabeculae. Bar $=50 \mu \mathrm{m}$; (B) PDL, IL and PDIL groups demonstrating the organization and thickening of bone trabeculae; abundant blood vessels (arrows) and intercellular matrix enriched with collagen fibers are shown $(*)$. A: apical third. Bar $=80 \mu \mathrm{m}$.
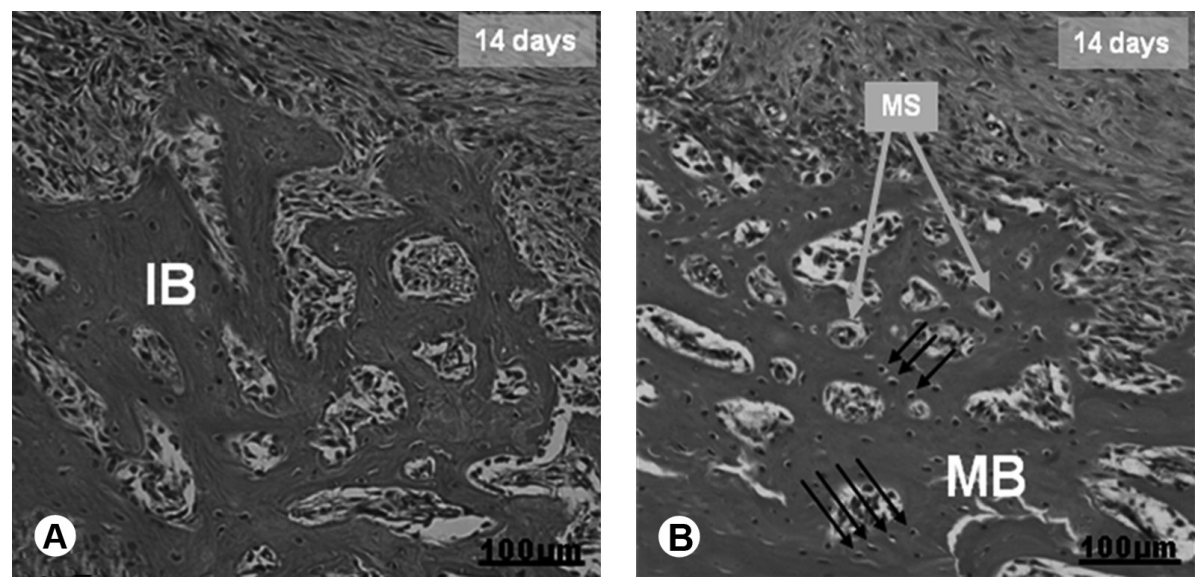

Figure 4. Representative HE-stained photomicrographs of groups at 14 days after the surgical procedure. (A) BC, L, P, PDP and IP groups showing the presence of bone trabeculae in the apical third and part of the middle third. Histological features of the immature bone (IB) are demonstrated. (B) PDL, IL and PDIL groups showing the presence of dense bone trabeculae with histological aspects suggesting osseous maturation, such as small medullar spaces (MS), and osteocytes organization (arrows). MB: Mature bone. Bar $=100 \mu \mathrm{m}$.

Table 1. Staining levels of vascular endothelial growth factor (VEGF) and osteocalcin at 7 days in the investigated areas

\begin{tabular}{|c|c|c|c|c|c|c|c|c|}
\hline & $\mathrm{BC}$ & $\mathrm{L}$ & $\mathrm{P}$ & PDP & $\mathrm{IP}$ & PDL & $\mathrm{lL}$ & PDIL \\
\hline \multicolumn{9}{|l|}{ VEGF } \\
\hline Endothelial cells & $0.23 \pm 0.03^{\mathrm{a}}$ & $0.19 \pm 0.06^{\mathrm{a}}$ & $0.17 \pm 0.05^{\mathrm{a}}$ & $0.18 \pm 0.09^{a}$ & $0.17 \pm 0.02^{\mathrm{a}}$ & $2.1 \pm 0.8^{\mathrm{b}}$ & $2.7 \pm 0.35^{b}$ & $2.9 \pm 0.75^{b}$ \\
\hline \multicolumn{9}{|l|}{ Osteocalcin } \\
\hline Osteoblasts/fibroblasts & $0.42 \pm 0.08^{a}$ & $0.26 \pm 0.04^{\mathrm{a}}$ & $0.22 \pm 0.04^{\mathrm{a}}$ & $0.26 \pm 0.07^{\mathrm{a}}$ & $0.27 \pm 0.05^{\mathrm{a}}$ & $2.3 \pm 0.7^{b}$ & $2.6 \pm 0.45^{b}$ & $2.8 \pm 0.56^{b}$ \\
\hline
\end{tabular}

Data are presented as mean and standard deviation of the mean from all sections analyzed per area. a,b letters represent intra-group analysis. Different letters differ statistically ( $p>0.05)$. 
alveolar bone is maintained by a complex orchestration of GF matrix molecules (e.g., osteopontin, and osteocalcin), immunologic mediators and cytokines, the controlled delivery of exogenous GFs to targets has shown to be efficient when performed in combination with biological carriers that allow the GFs to properly induce and enhance the healing process $(4,6,10,12,14,18)$.

Based on previous $(6,13,14)$ and present findings, was raised the hypothesis that liposomes promote the regulation of the concentration and spatiotemporal gradient of factors in rat tooth sockets. This hypothesis considers that the liposome matrix allows GFs to act at the place and time required by the therapy by increasing the retention of GFs at the treatment sites for sufficient time to allow cells to migrate to the injured area, proliferate and differentiate. Consequently, if the liposome drug delivery system improves GF bioavailability, therapy using these agents would become more advantageous, powerful and less invasive, whereas
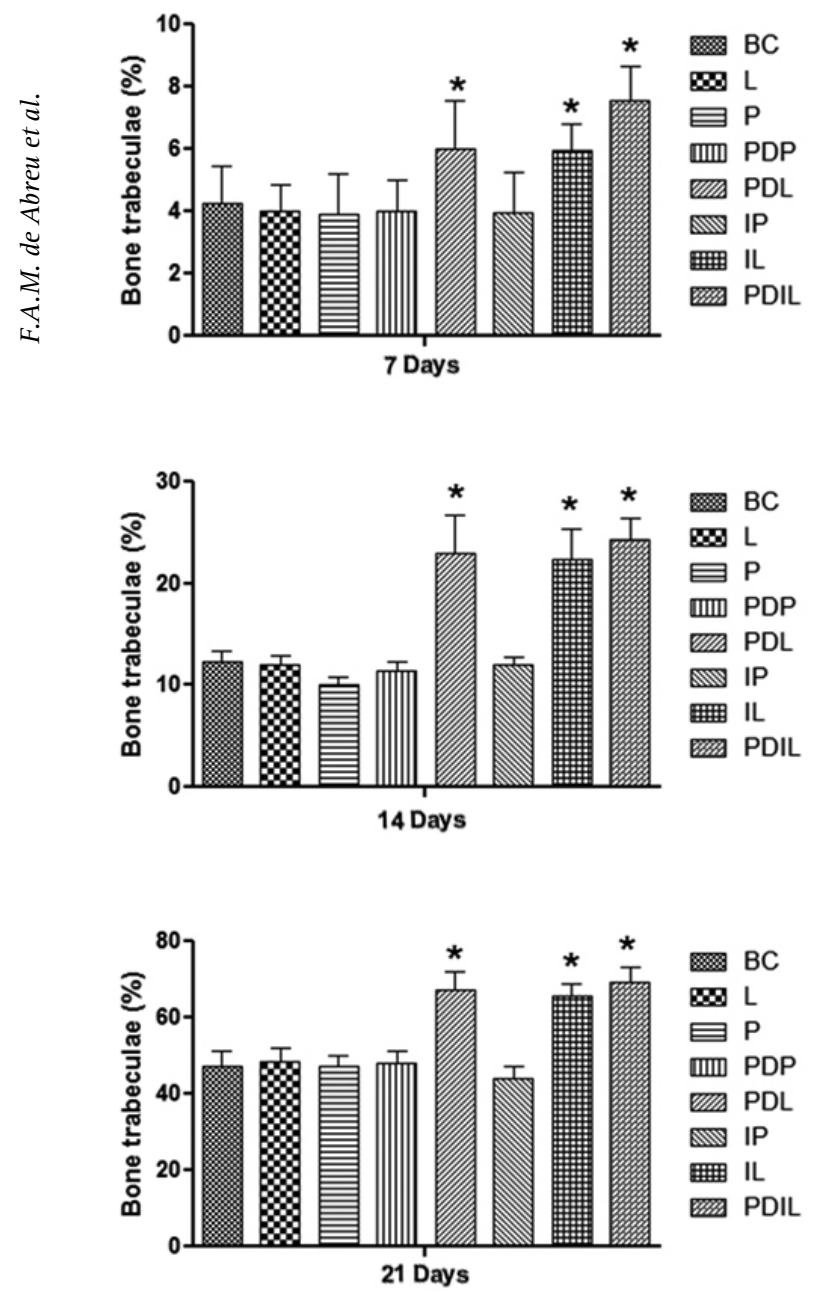

Figure 5. Quantification of bone trabeculae in tooth sockets at 7, 14 and 21 days after surgical procedures. Data are shown as mean \pm S.D. ${ }^{*} p<0.05$. the frequency and target of administration could be optimized in a manner to minimize overdosing and allow more objective and localized stimulation (4).

The histological and histoquantitative results of the current work identified an accelerated repair process during the evaluated periods. The repair process was more pronounced in the groups treated with isolated or combined GFs within liposomes, when compared with the other groups (BC, L, P, PDP and IP).

Therefore, it was postulated that the exogenous GFs were released properly and constantly following the wound requirement for those bioagents to assist the enrolment of mesenchymal cells to differentiate and reframe the alveoli.

The presence of multiple GFs is believed to be essential for most tissue regeneration processes (4), and according to the literature, combinations of different GFs may reveal interesting formulas to improve wound healing. Nevertheless, which GFs should be used and which combinations could be suitably administered to obtain enhanced repair signaling is crucial to decipher. In addition, an understanding of how these exogenous biological agents should be controlled and delivered to the injured tissue needs to be achieved. The nature of GF interactions, the best formulations that allow release with spatiotemporal control, the adequate GF concentration required, the most precise location of GFs and the length of GFs activity around the recovering tissue need to be considered (4).

With the aim of evaluating the potential of isolated or combined exogenous GFs on bone regeneration, this work assessed the effects of exogenous PDGF-BB and IGF-I on bone tissue repair. PDGF-BB is hypothesized to be a central connector between angiogenesis and osteogenesis, and could thus be used as a powerful therapeutic agent for bone regeneration and repair, by mobilizing and stimulating pericytes (mesenchymal stem cells) to organize and reproduce inside the wound (10).

In addition, IGF-I stimulates osteoprogenitor cell mitosis

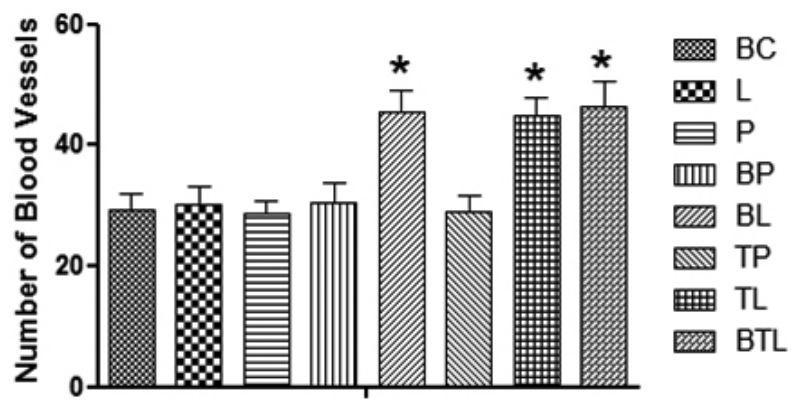

7 Days

Figure 6. Quantification of blood vessels in tooth sockets at 7 days after surgical procedure. Data are shown as mean \pm S.D. ${ }^{*} p<0.05$. 
and differentiation for maintaining general growth, which increases the number of mature osteoblasts. However, the effects of IGF-I local administration did not clearly reveale the actual potential of this GF for enhancing tissue regeneration for the already tested concentrations (4). Prior researchers studied the occurrence of IGF system members in the periodontum and alveolar bone of rat (7) and showed that the PDL acts as a reservoir of IGF components and that these GFs are involved in resorption processes, clastic activities, cementum homeostasis, odontoblast biology, fibrosis and pulp formation.

The combination of IGF-I with PDGF was effectively used by some researchers to heal soft tissues $(19,20)$ and bone (21-23), confirming the promising potential of this combined application for promoting bone regeneration in alveolar bone defects around implants or even after periodontal bone loss. Tanaka et al. (24) indicated IGF as a better stimulator of osteoblast marker expression in old bone and that PDGF slightly improves this effect. The PDGF-BB/IGF-I combination has an important role as a bone healing enhancer in both animal and human models (21).

In this study, it was found that PDGF-BB, IGF-I and the combination of these two GFs carried by liposomes may have a significant effect on bone repair capacity when compared with its free form (no liposomes). No significant differences were observed between the performances of the GF-liposome groups. The current findings are based on an in vivo model, which has the potential to permit further insight into the underlying mechanisms of bone repair and could support the identification of factors that stimulate
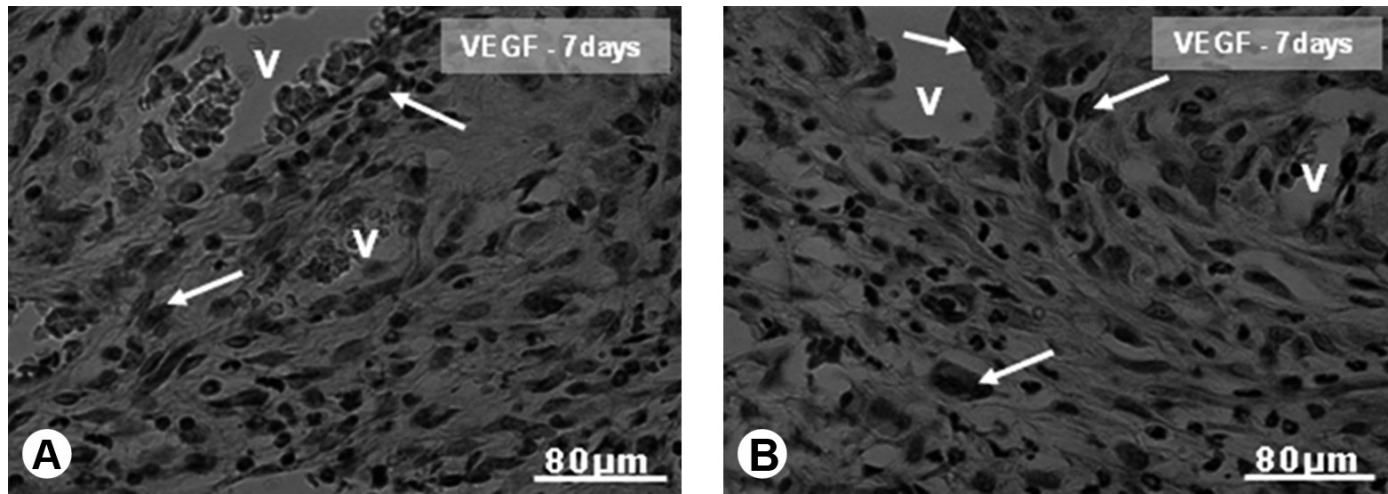

Figure 7. Representative photomicrographs of VEGF immunoreactivity in sockets at 7 days after the surgical procedure. (A) Sockets filled with a blood clot (BC) are indicated, and the BC, L, P, PDP, IP groups show weak reactivity (arrows). (B) Strong immunoreactivity is found in the PDL, IL and PDIL groups (arrows) V: Vessels. Bar $=80 \mu \mathrm{m}$.
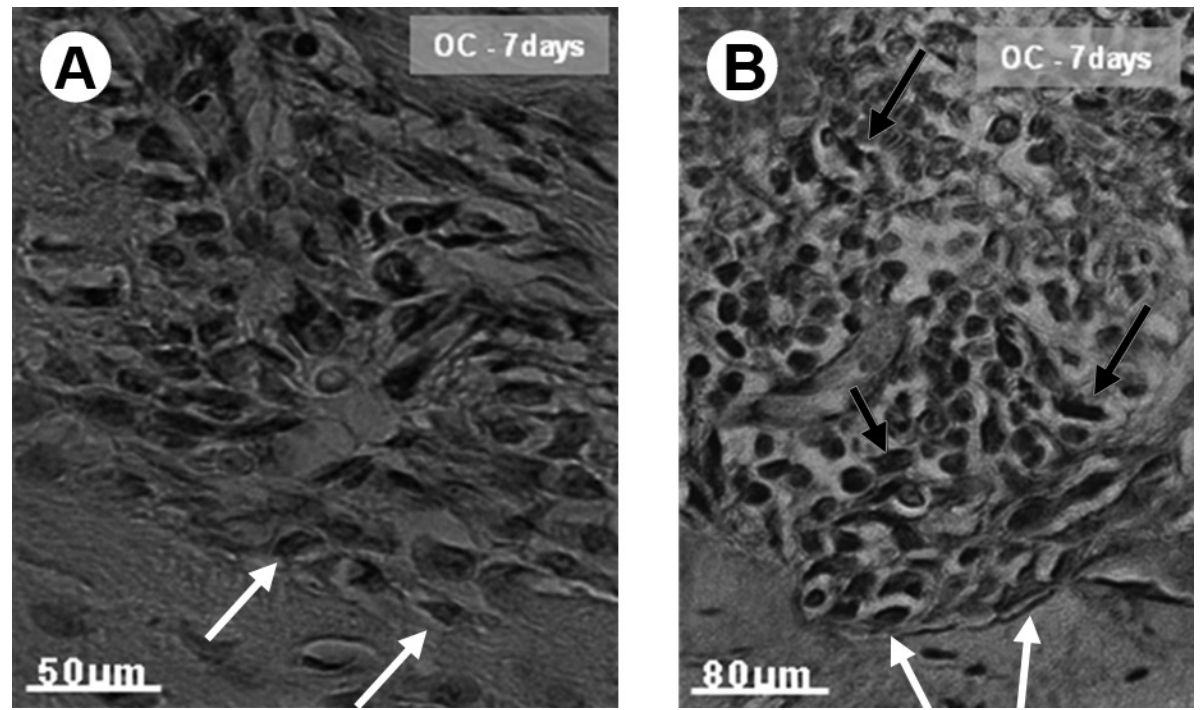

Figure 8. Representative photomicrographs of osteocalcin (OC) immunoreactivity in sockets at 7 days after the surgical procedure. (A) Sockets filled with blood clot (BC) are shown, and BC, L, P, PDP, IP groups show weak reactivity in osteoblasts (arrows). Bar $=50 \mu \mathrm{m}$. (B) Strong immunoreactivity in osteoblasts (white arrows) and fibroblasts (black arrows) is observed in the PDL, IL and PDIL groups. V: Vessels. Bar $=80 \mu \mathrm{m}$. 
the process in therapeutic approaches. Further evidence indicated that liposomes could be potential beneficial factors and an interesting biomaterial for delivering GFs in bone tissue engineering.

In fact, it was observed that alveolar bone repair occurs quicker in sites treated with GFs delivered within liposomes and consequently induces higher expression levels of reparative molecules such as VEGF and osteocalcin, which are essential to promote bone tissue repair. These two agents were indicative (markers) of the repair progress because VEGF is directly related to angiogenesis, by its role in the attraction of new endothelial cells into the injured site to form blood vessel. Osteocalcin, a key protein secreted by osteoblasts and settled in the extracellular matrix participates in the regulation of osteoblast function and the bone tissue mineralization stage. Thus, as more osteoblasts are formed in the alveoli, more osteocalcin will be present in the wound. In addition, the increasing number of blood vessels in the matrix indicates VEGF activity in the injured tissue.

In addition to the significant difference in the number of blood cells and the increase in trabecular bone in the GF-liposome groups at seven days after the surgical . procedure, the conducted immunohistochemical analyses identified a significant increase in VEGF and osteocalcin expression in the groups treated with PDGF-BB and IGF-I in liposomes, alone or in combination, when compared with the other groups. At the remaining periods, no significant differences in the expression pattern of these two markers were observed when comparing the GF-liposome groups with the BC, L, P, PDP and IP groups that received no GFs or had the GFs directly inserted without the carrier.

Concerning the used delivery system, the present work indicates liposomes as successful carriers for the controlled release and preservation of GF biological activity by protecting the GF from early absorption and degradation by proteases. This result agrees with those of other studies $(6,12-14)$. However, most of the currently studied delivering models used GF administration either through direct insertion or non-liposome carriers. These studies showed unsatisfactory results for spatiotemporal GF concentration and exposure time within the targeted site, especially because of direct absorption, unsafe levels of GFs and the consequent side effects of this type of therapy (25). In addition, few in vivo studies have been performed, and the alveolar microenvironment, a contaminated area, is a challenge for the success of the procedure.

In the present work, the insert experiment was performed using low concentrations of GFs when compared with direct administration. This procedure could be considered an advantageous therapy because of the diminished side effects that exogenous GF dosages could cause to patients.
This type of treatment using small concentrations of GFs administered alone or combined in liposomes became a potential strategy in the last few years. Therefore, the parameters to be studied in future tests include the exact GF needed dosage, the interaction or non-interaction between combined GFs, and the availability of endogenous GF receptors for properly activating the exogenous GF dosages. In addition, further studies should be performed to clarify the exact function and interaction dynamics of each GF at each stage of tissue regeneration, including inflammation, formation of granulation tissue, cell differentiation, matrix formation and remodeling.

Importantly, an increased percentage of trabecular bone was verified in GF-liposome groups, but no synergistic effect between IGF-I and PDGF-BB was observed. As PDGF$\mathrm{BB}$ is involved in angiogenesis and IGF-I is an osteogenic stimulator, these two GFs may participate in nonsimultaneous or non-consecutive steps of repair because these GFs do not share receptors competing for biochemical activation and may not cooperate synergistically when together. Future research may reveal the circumstances in which these GFs juxtapose or complete each other's functions. Currently, the knowledge of the complete and correct sequence of the natural signaling cascade that leads a tissue to heal is insufficient.

In conclusion, the study data suggest that GFs carried by liposomes, in either isolated or combined forms, enhanced the healing process in rat tooth sockets. The differential expression of the osteogenic markers VEGF and osteocalcin in the early phases of bone healing support these findings.

\section{Resumo}

Este trabalho avaliou o potencial de formação óssea do fator de crescimento derivado de plaquetas na isoforma BB (PDGF-BB), fator de crescimento semelhante à insulina I (IGF-I), e a mistura PDGF-BB/IGF-I administrada em lipossomas comparando com tampão fosfato salino (PBS), no processo de cicatrização de alvéolos dentários de ratos. Cento e doze ratos Wistar foram distribuidos aleatoriamente em 7 grupos de 16 animais cada e foram avaliados aos 3, 7, 14 e 21 dias após a extração dos segundos molares maxilares. Os alvéolos esquerdos foram tratados com PBS (P), lipossomas vazios (L), IGF-I em PBS (IP), IGF-I em lipossomas (IL), PDGF-BB em PBS (PDP), PDGF-BB em lipossomas (PDL) e ambos os fatores de crescimento (GFs) em associação dentro de lipossomas (PDIL). Os alvéolos direitos foram preenchidos com coágulo sanguíneo (BC). As análises histomorfométrica e histológica foram utilizadas para avaliar a formação de novo osso e vasos sanguíneos. Imunohistoquímica foi realizada para avaliar a expressão de osteocalcina e o fator de crescimento endotelial vascular (VEGF) durante o reparo ósseo. Os dados foram testados estatisticamente utilizando o teste de Tukey em acordo com análise de Dunn e o teste Mann-Whitney U seguido pela análise de um passo de Kruskal-Wallis. Os resultados foram considerados significantes quando $p<0,05$. Uma percentagem altamente significativa de osso trabecular e alto número de vasos sanguíneos foram observados nos grupos IL, PDL e PDIL $(p<0,05)$. Todavia, esses grupos lipossoma-GF tiveram resultados similares estatisticamente. Ensaios de imunohistoquímica inicialmente detectaram a expressão de osteocalcina e VEGF aos 3 dias, seguida por um pico aos 7 dias. Niveis mais baixos de imunorreatividade foram observados em BC, L, P, PI e PDP quando comparados com os grupos IL, PDL e PDIL 
$(p<0,05)$. Os resultados sugerem que GFs carreados por lipossomas, na forma isolada ou em combinação, aceleram o processo de cicatrização em alvéolos dentários de rato. A expressão diferencial dos marcadores osteogênicos VEGF e osteocalcina, nas fases iniciais de cicatrização óssea, confirma esses achados.

\section{Acknowledgements}

This study was supported in part by PAPE-PRPq (Pró-Reitoria de Pesquisa UNIUBE) and FAPEMIG (Fundacão de Amparo a Pesquisa de Minas Gerais).

\section{References}

1. Araújo $M G$, Lindhe J. Ridge alterations following tooth extraction with and without flap elevation: An experimental study in the dog. Clin Oral Implants Res 2009;20:545-549.

2. Pelegrine AA, Costa CES, Correa MEP, Marques Junior JFC. Clinical and histomorphometric evaluation of extraction sockets treated with an autologous bone marrow graft. Clin Oral Implants Res 2010;21:535542.

3. Fernandes PG, Novaes Junior AB, Queiroz AC, Souza SLS, Taba Junior M, Palioto $\mathrm{DB}$, et al.. Ridge preservation with acellular dermal matrix and anorganic bone matrix cell-binding peptide $\mathrm{P}-15$ after tooth extraction in humans. J Periodontol 2011;82:72-79.

4. Chen FM, Zhang M, Wu ZF. Toward delivery of multiple growth factors in tissue engineering. Review. Biomaterials 2010;31:6279-6308.

5. Javed F, Al-Askar M, Al-Rasheed A, Al-Hezaimi K. Significance of the platelet-derived growth factor in periodontal tissue regeneration. Arch Oral Biol 2011;56:1476-1484.

6. Ferreira $C L$, Abreu FAM, Silva GAB, Silveira FF, Barreto LBA, Paulino TP, et al.. TGF- $\beta 1$ and BMP-4 carried by liposomes enhance the healing process in alveolar bone. Arch Oral Biol 2013;58:646-656.

7. Götz W, Kunert D, Zhang D, Kawarizadeh A, Lossdörfer S, Jäger A. Insulin-like growth factor system components in the periodontium during tooth root resorption and early repair processes in the rat. Eur J Oral Sci 2006;114:318-327.

8. Allori AC, Sailon AM, Warren SM. Biological basis of bone formation, remodeling, and repair - Part I: Biochemical signaling molecules. Tissue Eng Part B Rev 2008;14: 275-283.

9. Behnia H, Khojasteh A, Soleimani M, Tehranchi A, Atashi A. Repair of alveolar cleft defect with mesenchymal stem cells and platelet derived growth factors: A preliminary report. J Cran Maxi Faci Surg 2011;40:2-

10. Caplan Al, Correa D. PDGF in bone formation and regeneration: new insights into a novel mechanism involving MSCs. J Orthop Res 2011;29:1795-1803.

11. Liu J, Xu L, Li Y, Ma J. Temporally controlled multiple-gene delivery in scaffolds: A promising strategy to enhance bone regeneration. Med Hypotheses $2011 ; 76: 173-175$.

12. Saddi KR, Alves GD, Paulino TP, Ciancaglini P, Alves JB. Epidermal growth factor in liposomes may enhance osteoclast recruitment during tooth movement in rats. Angle Ortho 2008;78:604-609.
13. Alves JB, Ferreira $C L$, Martins $A F$, Silva GAB, Alves GD, Paulino TP, et al.. Local delivery of EGF-liposome mediated bone modeling in orthodontic tooth movement by increasing RANKL expression. Life Sci 2009;85:693-699.

14. Marquez L, de Abreu FA, Ferreira CL, Alves GD, Miziara MN, Alves $J B$. Enhanced bone healing of rat tooth sockets after administration of epidermal growth factor (EGF) carried by liposome. Injury 2012;44:558-564.

15. Mendes RM, Silva GAB, Lima MF, Caliari MV, Almeida AP, Alves JB, et al.. Sodium hyaluronate accelerates the healing process in tooth sockets of rats. Arch Oral Biol 2008;53:1155-1162.

16. Reis-Filho CR, Silva ER, Martins AB, Pessoa FF, Gomes PV, Araújo MS, et al.. Demineralised human dentine matrix stimulates the expression of VEGF and accelerates the bone repair in tooth sockets of rats. Arch Oral Biol 2011;31:350-358.

17. Fernandes AM, Silva GAB, Lopes Junior N, Napimoga MH, Benatti BB, Alves JB. Direct capping of human pulps with a dentin bonding system and calcium hydroxide: an immunohistochemical analysis. Oral Surg Oral Med Oral Pathol Oral Radiol Endod 2008;105:385-390.

18. Tayalia $\mathrm{P}$, Mooney DJ. Controlled growth factor delivery for tissue engineering. Adv Mater 2009;21:3269-3285.

19. Wagner W, Wehrmann M. Differential cytokine activity and morphology during wound healing in the neonatal and adult rat skin. J Cell Mol Med 2007;11:1342-1351.

20. Etheredge L, Kane BP, Hassell JR. The effect of growth factor signaling on keratocytes in vitro and its relationship to the phases of stromal wound repair. Invest Ophthalmol Vis Sci 2009;50:3128-3136.

21. Lynch SE, Buser D, Hernandez RA, Weber HP, Stich H, Fox $\mathrm{CH}$, et. al.. Effects of the platelet-derived growth factor/insulin-like growth factor-I combination on bone regeneration around titanium dental implants. Results of a pilot study in beagle dogs. J Periodontol 1991;62:710-716.

22. Becker W, Lynch SE, Lekholm U, Becker BE, Caffesse R, Donath $K_{\text {, et }}$ al.. A comparison of ePTFE membranes alone or in combination with platelet-derived growth factors and insulin-like growth factor-I or demineralized freeze-dried bone in promoting bone formation around immediate extraction socket implants. J Periodontol 1992;63:929-940.

23. Giannobile WV, Hernandez RA, Finkelman RD, Ryan S, Kiritsy CP, D'Andrea $\mathrm{M}$, et al.. Comparative effects of platelet-derived growth factor-BB and insulin-like growth factor-I, individually and in combination, on periodontal regeneration in Macaca fascicularis. J Periodontal Res 1996;31:301-312.

24. Tanaka $H$, Wakisaka $A$, Ogasa $H$, Kawai $S$, Liang CT. Effect of IGF-I and PDGF administered in vivo on the expression of osteoblast-related genes in old rats. J Endocrinol 2002;174:63-70.

25. Schmidmaier G, Wildemann B, Heeger J, Gäbelein T, Flyvbjerg A, Bail HJ, et al.. Improvement of fracture healing by systemic administration of growth hormone and local application of insulin-like growth factor-1 and transforming growth factor- $\beta 1$. Bone $2002 ; 31: 165-172$

Received April 29, 2013 Accepted July 13, 2013 